\title{
Students' perceptions on the effectiveness of product placements: A case study of a private higher education institution in Durban
}

\author{
A. Koopman \\ S. Perumal \\ K. Perumal \\ M. Williamson \\ Z.E. Cebisa \\ University of KwaZulu-Natal, Westville Campus, South Africa
}

\begin{abstract}
Keywords
Digital and social media advertising; Product placement; Sales promotions; Sponsorships; Traditional advertising.
\end{abstract}

\begin{abstract}
The aim of the study was to investigate students' perceptions of the effectiveness of product placements and to determine whether they are aware of product placements, whether they pay any attention to product placements and whether the exposure to product placements has influenced their purchasing behaviour in any way. This study adopted a quantitative research approach and employed the case study design; hence, the main focus of this study is on how students, based at private higher institution in Durban, perceive the effectiveness of product placement. The study was conducted at a private higher education institution with an estimated population of 1000; the sample size was 135. The form of non-probability convenience sampling method was employed. Although the form of nonprobability sampling techniques is not common in quantitative studies, sufficient representation was ensured. Hence, the research results were able to be generalised from a sample to a population. Quantitative data was collected using the questionnaire method. SPSS statistical package was used to capture numerical data. The study also employed both descriptive and inferential statistics in order to infer the sample results to the entire population.

The quantitative data analysis results indicated that product placements are similar to traditional advertising in terms of capturing the audience's attention, developing positive feelings towards the product and recall when faced with a purchase decision. The study has also contributed immensely to the digital and social media advertising theory and practice.
\end{abstract}

\section{Introduction}

Product placement has been defined as the paid inclusion of branded products through audio or visual means and is generally found within mass media programming (Schmoll, Hafer, Hilt, and Reilly, 2006). Schmoll et al. (2006) have noticed a significant increase in the use of these promotional tactics, where companies are prepared to spend millions of dollars on such campaigns. The youth are perceived to be a lucrative market for many companies; as their purchasing power increases, so does their value to the organisation. This results in marketers at times competing aggressively to capture this group and to develop and maintain long-lasting and profitable relationships with them. According to Cowley and Barron (2008), product placements have significant advantages over traditional advertising. They hold that product placements are better than advertising in terms of memory and choice. Consumers are exposed to high volumes of marketing communication messages and the effectiveness of these promotional messages can thus be questioned (Williams, Petrosky, Hernandez, and Page Jr, 2011). Marketers are under increasing pressure to create awareness of their product/s and to stimulate an interest that will ultimately lead to the trial and adoption of the product.

The increasing popularity of reality television shows, such as "The Apprentice", has created opportunities for product placement; as marketers attempt to benefit from the success of well-known programmes, these programmes have the ability to stimulate interest and create excitement. Factors such as the consumer's resistance towards advertisements, which is largely due to their higher levels of scepticism, together with the fragmentation of traditional media and marketers' growing attraction 
towards non-traditional media, have led to the adoption of this form of communication (Balasubramanian, Karrh, and Patwardhan, 2006).

The advancement of technology has given consumers, or viewers, more options. They now have the ability to zip, zap and mute communication messages, which has prompted marketers to think of unique ways to create exposure and a desire for their products. Approximately 43.6 million Americans are now using technology advancements such as digital video recorders (DVRs). According to Begy and Talwar (2016), the use of digital video recorders together with the legal/illegal streaming of non-commercialised content, has led to the ineffectiveness of the traditional "30 second spot" advertisement.

\section{Problem Statement}

Although marketers seem to have a dilemma and need to evaluate the value that product placements can bring. The changes in the technological environment has brought more options to consumers and has affected the manner in which students at private higher institutions perceive the effectives of product placement.

\section{Hypotheses}

H1: The awareness of product placements is significantly related to the students' year of study.

$\mathrm{H} 2$ : The awareness of product placements is significantly related to the faculty students belong to.

H3: There is a positive and significant relationship between the attention given to product placements and when a student has a pre-existing need.

H4: There is a positive and significant relationship between the attention given to product placements and when a student has a positive attitude towards the product.

H5: There is a significant relationship between feelings towards product placements when the student has a pre-existing need.

H6: There is a significant relationship between feelings towards product placements when the student has a positive attitude towards the product.

H7: There is a positive relationship between the recall of product placements and those placements that are considered to be more intrusive.

H8: There is a significant and positive relationship between product placements and purchasing behaviour.

\section{Literature Review}

This section provides an insight into the work of previous scholars regarding modes of product placements, attitudes towards product placements, advantages and disadvantages, product placements within emerging market and ethical concerns of product placements.

\section{Modes of product placement}

Product placement forms part of a larger segment of marketing services that fall under the banner of branded entertainment (Cowley and Barron, 2013). Placements can be unintentional and unpaid, voluntary and involuntary (Balasubramanian, Karrh, and Patwardhan, 2006). The process involves the integration of an advertiser's product into selected media, most often television and films for clear visibility (Cowley and Barron, 2008). Although visible, the product is often not the focus as the viewers' attention is usually on the plot or story line. Marketers need to ensure that there is a fit between the product or brand and the plot or scene of a film (Cowley and Barron, 2008). Lacroix and Martin (2013) have identified three product placement strategies; these include visual only, audio only and a combination of audio and visual.

Visual only - This involves the demonstration of a product, logo, billboard or other brand identifier without any accompanying message or sound. There is significant risk in this approach, as there is a strong likelihood that the product will not be noticed. The brand, the logo or the products of the firm are presented passively. The product placement forms part of the background and the benefits of the product are not communicated.

Audio only - The brand is not shown but is mentioned in film dialogue and carries the same risk as the visual approach. Typical examples of this approach include sponsorships of television programmes. 
Combined audio-visual - This is a combination of the first two strategies. It requires more creativity, and the costs are higher. With this strategy, the brand, logo, firm, or product play a more active role in the scene and are expressed formally within the programme or plot. Lacroix and Martin (2013) pointed out that the benefits of the product are clearly communicated and as a result have a greater influence on viewers. An example of this can be found in the movie, "Harold and Kumar go to White Castle", where the brand name is mentioned and seen in the movie and also features in the title of the movie.

The ineffectiveness of visual only and audio only placements has led marketers to use a combined audio-visual approach. Although the combined approach is believed to be more effective in achieving organisational goals, the context in which the placement is shown has an impact on the reaction of the consumer (Gupta and Lord, 1998). Marketers thus have a dilemma and need to evaluate the value that product placements can bring. Audio-visual placements generate higher levels of recall, but the cost associated with this approach can be a limiting factor in its adoption.

Placements in any of the three modes can be said to be either prominent or subtle. Prominent placements refer to those in which the product is highly visible, largely due to its size, central positioning on the screen or integration into the plot of a movie or television programme (Gupta and Lord, 1998). Subtle placements receive less attention, they are not core to the plot and are sometimes mixed with other brands, in a scene limiting exposure and the ability to capture the attention of viewers. Subtle placements are often questioned in terms of the ability to meet marketing communication objectives. Marketers are often faced with a trade-off in terms of costs and the degree of prominence, as highly visible placements are more expensive to the organisation (Gupta and Lord, 1998).

The products central to the plot of a television episode were recalled more easily than those featuring in the viewer's peripheral vision (Nebenzahl and Secunda, 1993). Their research had a strong focus on the effectiveness of the various modes of product placement. Their findings revealed that product placements that were heard but not seen in the episode were better recognised than products that were seen but not heard. The decision of whether to make use of audio or visual placements and whether to have the product feature prominently and vividly in the plot of the episode or whether it should be featured peripherally is one that should be taken seriously by marketers and advertisers alike, as it can have a major impact on the return received from product placements (Lacroix and Martin, 2013).

Later research conducted by Homer (2009) evaluated consumers' attitude towards product placements with respect to the mode of placement used. Their findings were conclusive in that consumers' attitudes tend to depreciate when obvious product placements are repeated too often. Prominent placements are viewed as being distracting and less believable and realistic and seen as interfering with the plot line of the movie or programme. The repetition of prominent placements results in viewers developing a negative attitude towards the product or brand, as they become aware that the product is strategically placed for commercial gain, rather than being used legitimately in the plot.

Advertisers have believed that the use of prominent stimuli is effective in getting attention and enhancing attitudes but research by Homer (2009) was inconclusive in supporting this correlation. Homer (2009) acknowledges that product placement can have a positive effect on the consumer's memory but is largely ineffective in changing their attitude towards the product or brand. The research mentions the importance of the character that is featured with the product or brand. Favourable characters are likely to be more persuasive in influencing behaviour.

Figure 1: Modes of product placement

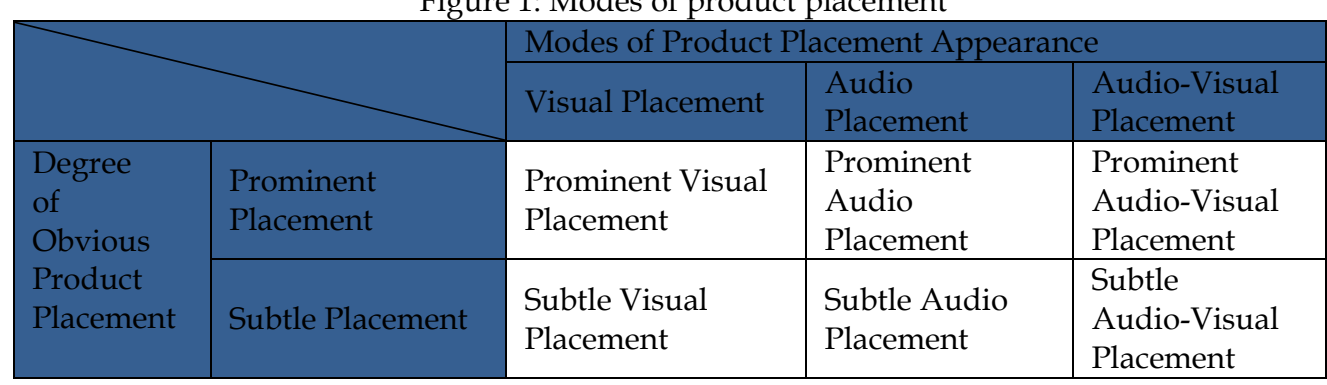

(Gupta and Lord, 1998) 


\section{Attitudes towards product placements}

In figure 1, attitudes seem to play a critical role in product placement appearance, whether it is visual, audio, or audio-visual placement. Attitudes can be described as hypothetical constructs, which cannot be seen, touched, heard, or smelled (Sabour, Pillai, Gistri, and Balasubramanian, 2015). Attitudes are typically associated with the feelings that an individual has developed, either positive or negative and serve as a means through which to evaluate someone or something (Gupta and Lord, 1998).

Marketing theorists often make reference to the three elements of attitudes, namely cognitive, affective, and behavioural (Nebenzahl and Secunda, 1993). The cognitive component refers to an individual's knowledge and perceptions that are acquired through direct experience. Knowledge, perception, and beliefs may not necessarily be true but as long as they are evident, they have the ability to influence consumer behaviour. The affective component relates to the feelings or emotions that an individual has developed towards a product or brand. These feelings are formulated from a variety of sources and dictate the level of attention a viewer gives to marketing communication messages. For example, if an individual has a negative feeling towards a particular brand of vehicle because of internet articles and negative stereotypes, they are less inclined to pay attention to advertisements and the product placement initiatives of that brand. The third element of attitude is behavioural. Behavioural component can be defined as the 'action' stage and is the sum of the earlier two components. If an individual has developed a positive perception of a brand and has a positive emotional connection, they are more likely to purchase products affiliated to that brand (Nebenzahl and Secunda, 1993).

Viewers have become more knowledgeable with regard to organisations' promotional tactics. Their level of scepticism and trust is indicative of their lack of belief. Higher levels of scepticism are usually accompanied by negative attitudes towards marketing communications in general, which can transcend into product placements (Kjærnested and Nielsen, 2012). Attitudes also affect the way in which individuals' judge and react towards other people, objects, and events (Parumasur and Roberts-Lombard, 2014). Attitudes towards advertising in general are thought to have an influence on both the attitude towards the particular advert and the attitude towards the brand. Consumers who have a positive attitude towards advertising are thought to have a more positive attitude towards the product or brand being advertised. Product placement as a form of marketing communication shares these properties (Gupta and Gould, 1997). Positive attitudes towards a product translate into the development of positive word of mouth, favourable perceptions, and higher levels of recall (Srivastava, 2016).

\section{Advantages and disadvantages of product placements}

There are significant advantages to using product placements within the overall marketing communication strategy (Górska-Warsewicz and Kulykovets, 2017). One of which is that the viewer is unable to avoid exposure. Higher levels of exposure are often associated with higher levels of recall (Cowley and Barron, 2008). Product placements can also result in viewers having a more positive attitude towards the brand as a result of the exposure. The exposure to any stimuli allows the viewer to formulate an image about a product or brand. The use of product placement can trigger the formulation of positive brand associations (Cowley and Barron, 2008). Furthermore, the cost accompanying the production of movies and television programmes can be excessive. Product placements are sometimes used to offset these costs, it has the ability to reach captive audiences, it can provide greater reach than traditional advertising and it features the brand usage in a natural setting. It is a strategy that could be adopted by products seen as unethical or those that are prohibited from featuring in traditional mass media due to strict advertising regulations (Kamleitner and Jyote, 2013).

Exposure of the product is a substantial advantage. This coupled with the DVD rental and film broadcasting of a movie, results in a communication strategy that can have a high level of impact. Film stars in the $21^{\text {st }}$ century carry significant power and can influence consumer purchasing behaviour. With film attendees being exposed to the product and witnessing their favourite film stars using the product, the impact of a placement can be heightened. In addition, the costs associated with product placements are significant and the reach and exposure it is able to generate for a brand make it a good "value for money" strategy. Research conducted by Gupta and Lord (1998) concluded that viewers were able to recall $38 \%$ of products placed in featured films. 
However, as with other forms of marketing communication there are noticeable weaknesses or limitations. One of the main limitations of product placements is the inability to truly measure the impact that it has on consumers. The over exposure of products, through advertising or any other communication tool including product placements, can change the viewers attitude towards the product or brand. This over exposure can inform viewers of the persuasive intent of the organisation, it interrupts their viewing experience and can result in a negative attitude forming towards the brand (Cowley and Barron, 2008). There are significant costs attached to product placements. The high absolute costs associated with this marketing communication method mean that this is not a viable strategy for many small organisations (Gupta and Lord, 1998). There is also substantial risk attached to product placements, as there is no guarantee that the product will be noticed by viewers.

The nature of this medium has evolved to a level where the competition between companies is intense. Higher levels of competition and the desperation of organisations to expose their products and brands have resulted in higher costs. Marketers and advertisers have little influence over the featuring of their product. The product may be used in an unfavourable scene or by an unfavourable character, which changes the viewer's mood and attitude towards the product and brand altogether (Kamleitner and Jyote, 2013).

\section{Product placements within emerging markets}

The saturation of markets within developed countries such as the United States of America (USA), France, Australia, and Japan, have resulted in marketers turning their attention to opportunities with developing countries (Srivastava, 2016). Numerous organisations have identified largely untapped consumer markets in parts of Africa, with limited competition. This compares favourably to the European market, which is characterised by a saturated market and lower population growth rates. Population increase, a growing middle class and increased levels of economic development have improved many African countries' market attractiveness.

There has been a limited amount of research conducted on product placements outside the USA and even fewer studies in emerging markets (Srivastava, 2016). Product placements in emerging markets such as India provide viable marketing opportunities, as the movie industry and the development of Bollywood reaches greater heights, its impact can extend to locations all over the world (Srivastava, 2016).

Emerging markets such as Brazil, India, Russia, China, and South Africa are of paramount importance for global brands. These markets often represent infinite possibilities and opportunities to expand a brand and build brand equity and brand loyalty. In India more than 1000 movies are released each year. This places pressure on marketers and advertisers to not only use product placements as a marketing communications approach but also to use it effectively to ensure that brand awareness, brand recall and brand equity are enhanced (Srivastava, 2016).

Research conducted by Srivastava (2016) in India concluded that the prominence of brand placements had a positive effect on brand memory. They emphasised that consumers were better able to remember brands that were placed in successful films. This highlights the need for marketers to not just place their products or brands in all movies, but to be strategic about choosing blockbusters. The research also highlighted the correlation between the length of the product placement and brand recall, with higher levels of exposure often generating higher levels of brand recall. However, marketers need to be mindful that high levels of exposure can result in irritation for the viewer, which ultimately leads to lower levels of brand equity and a negative association with the brand developing.

\section{Ethical concerns of product placements}

The issue of ethics is not limited to product placements but extends to all other forms of marketing communications, including advertising. Marketing communication has become notorious for pushing ethical boundaries and marketers and advertisers alike are often seen using deceptive practices to influence behaviour and induce a purchase. Some of the issues under the spotlight include truth in marketing communication advertising to children, promoting controversial products and providing substantiation for claims that are made (Cant and van Heerden, 2013). 
The controversy surrounding product placements is enhanced by the fact that product placements represent a hybrid message comprised of advertising and publicity in which marketers or advertisers may appear to be working around advertising restrictions in other media, such as television (Khan, Mahmood, Lodhi, and Aftab, 2016). It is this level of deception that is frowned upon by critics. For example, some countries, including South Africa, have limited tobacco manufacturers from being involved in advertising and sponsorships (Gupta and Gould, 1997).

Ethical concerns regarding product placements are strongly linked to the fact that it is regarded as an element of marketing communications. Khan et al. (2016) concluded that the attitude that one develops towards a product has a positive relationship with the purchase intention. Therefore, those consumers who have a positive attitude towards a product or brand are more inclined to purchase that particular product. Another concern emerges from the fact that several critics believe that product placements have a negative economic impact in that moviegoers will develop a positive opinion of products that are associated with the glamour of Hollywood and ignore other, more product-centred factors.

\section{Methodology}

The study was undertaken with various tertiary students at a private higher education institution in Durban, utilising quantitative research methodology. The adoption of the quantitative research approach was informed by the research problem that the study intended to address. The study on the perspectives of students regarding product placement allows the research sample results to be generalised to the entire population (Keller, 2018). The case study research design was employed as the main focus was on students studying at private higher education institution. The research study employed non-probability sampling techniques and in particular, the convenience sampling method, where the researcher's plan involved selecting students who were on campus during a particular time frame. The use of convenience sampling meant that only those students who were on campus at the same time as the researcher had a chance of being selected to participate in the study. Non-probability sampling methods are known to be more time efficient, convenient, and cheaper, making them more suitable for researchers who require information promptly in order to make decisions (Wiid and Diggines, 2009). Creswell and Clark (2011) further argued that non-probability sampling techniques are not representative samples, however, such techniques can be adopted provided there is a sufficient representation of participants.

The campus itself has more than one thousand students from various ethnic and cultural backgrounds. These students are split across four faculties, namely, Commerce, Humanities, Information Technology and Social Sciences. The surveys were personally administered over the course of three days. A sample size of one hundred and thirty-five was chosen for this study, including students from all four faculties. A high percentage of students at the institution belong to the Faculty of Commerce, which is evident in the number of participants who belong to this faculty. A questionnaire using closed-ended questions and a 5-point Likert scale was designed and administered to students. Quantitative data was collected and analysed using the Statistical Package for the Social Sciences (SPSS) and MS Excel.

In terms of data analysis, the researchers used univariate analysis, which refers to the examination of only one variable at a time. Univariate analysis uses measures of central tendency and dispersion and particularly useful when describing a data set where much of the interpretation is left to the researcher (Wiid and Diggines, 2009). The nature of the research study being quantitative, allowed for the use of tables to indicate frequency, proportion or percentage and graphics such as histograms, frequency and polygons and pie charts. The data was essentially analysed using descriptive and inferential statistics. The Chi-square goodness of fit test was also used and is considered to be applicable where the researchers wish to examine the relationship or association between variables. The calculations in this kind of analysis are based on the two-way, cross-tabulation of the two variables. The Chi-square tests were used to assess whether the variables that were analysed are independent or dependent. The Chi-square test is only valid if the expected cell sizes are not too small. A rule of thumb is that no cell should have an expected frequency of less than 5 (Maree, 2007).

Binominal tests were also used in this study. They are mainly associated with tests where an experiment has two possible outcomes. In this study the binominal test was used to test whether a significant proportion of the respondents selected one of a possible two responses. This can be extended 
when data with more than 2 response options is split into two distinct groups. The use of $\mathrm{t}$-tests was extended to this study. T-tests are used when two independent groups need to be compared based on their average score on a quantitative variable (Maree, 2007). Two specific t-tests were used, namely one sample t-test and the independent sample t-test. The former was used to assess whether the mean score was largely different from that of the scalar and the latter was used to compare two independent groups of cases.

\section{Discussion of Results}

The table 1 below, presents demographical information of the research participants. This section is significant as the research seeks to determine if demographic variables affect the manner in which students perceive product placement.

Table 1: Respondents demographics

\begin{tabular}{|c|c|c|c|c|c|c|c|}
\hline Variables & Category & Frequency & $(\%)$ & Variables & Category & Frequency & $(\%)$ \\
\hline \multirow[t]{4}{*}{ Gender } & Male & 58 & 43 & $\begin{array}{ll}\text { Level of } \\
\text { study }\end{array}$ & $1^{\text {st }}$ year & 73 & 54,1 \\
\hline & Female & 77 & 57 & & $2^{\text {nd }}$ year & 40 & 29,6 \\
\hline & & & & & $3^{\text {rd }}$ year & 13 & 9,6 \\
\hline & & & & & Honours & 9 & 6,7 \\
\hline \multirow{8}{*}{$\begin{array}{l}\text { Ages } \\
\text { (Years) }\end{array}$} & 18 & 21 & 15,6 & Faculty & Commerce & 91 & 67,4 \\
\hline & 19 & 45 & 33,3 & & Humanities & 18 & 13,3 \\
\hline & 20 & 27 & 20,0 & & $\begin{array}{l}\text { Information } \\
\text { Technology }\end{array}$ & 17 & 12,6 \\
\hline & 21 & 21 & 15,6 & & $\begin{array}{l}\text { Social } \\
\text { Sciences }\end{array}$ & 9 & 6,7 \\
\hline & 22 & 9 & 6,7 & & & & \\
\hline & 23 & 5 & 3,7 & & & & \\
\hline & 24 & 0 & 0 & & & & \\
\hline & $25+$ & 7 & 5,2 & & & & \\
\hline
\end{tabular}

Table 1 above, was the first section of the questionnaire which addressed the demographic information of respondents. The sample comprised of $57 \%$ female (77 respondents) and $43 \%$ male (58 respondents). In terms of age, 33,3\% of respondents were 19 years old, which exemplifies the higher-class sizes amongst first year groups; $84,4 \%$ of respondents were between the ages of 18 and 21 . The level of study of respondents was characterised as $54,1 \%$ first year students, $29,6 \%$ second year students, $9,6 \%$ third year students and 6,7\% honours year students. In terms of the student's faculty, $67,4 \%$ of respondents belong to the Faculty of Commerce, 13,3\% belong to the Faculty of Humanities, 12,6\% belong to the Social Sciences Faculty and 6,7\% of respondents belong to the Information Technology Faculty.

\section{Major Findings}

This section presents major findings which is based on interpretation of the p-value. This value provides guidelines on whether there is strong or weak evidence against the hypothesis.

\section{Awareness}

Although organisations spend infinite sums of money on strategically placing their products in movies, series, and other media, only $76(56 \%)$ of the respondents were aware of the concept of product placement and that companies and brands use these tactics extensively to appeal to their target market. The level of awareness was further analysed per faculty and per year of study. The results revealed that there is a significant relationship between the awareness of product placements and the level of study $x^{2}$ $(3)=10.315, p=.016$. This alternate hypothesis is accepted. There is weak evidence that the relationship between awareness of product placement and level of study are likely to exist. All Honours students indicated that they are aware of the concept of product placements, while a significant number of those not aware are in their $2^{\text {nd }}$ year of study. 
Results further revealed that there is a significant relationship between awareness of product placements and the faculty a student belongs to $\chi^{2}(3)=9.984, p=.019$. This hypothesis is accepted against null. There is weak evidence that the relationship between awareness and the faculty students belong to might not exist. The majority of students belonging to the Faculty of Social Sciences indicated that they were not aware of product placements. This statistic could be as a result of these students not completing any Business Management or Marketing Management modules in their qualifications and subsequently not being exposed to the concept. This finding contradicts literature findings. Soba and Aydin (2013) and, Russell and Rasolofoarison (2017) argued that humankind is exposed to product placement in mainstream media, occasionally even without knowing it.

\section{Attention}

The results indicated that more attention is paid to product placements when: a) there is a preexisting need $(\mathrm{M}=3.87, \mathrm{SD}=.718), \mathrm{t}(75)=10.541, \mathrm{p}<.0005$. This alternate hypothesis is accepted in favour of null hypothesis as there is a very strong evidence that under no circumstances less attention can be paid to product placements when there is a pre-existing need; $b$ ) there are positive attitudes towards the product $(\mathrm{M}=4.04, \mathrm{SD}=.824), \mathrm{t}(75)=11.002, \mathrm{p}<.0005 ; \mathrm{c})$ a celebrity is featured in the product placement $(\mathrm{M}=3.54, \mathrm{SD}=1.012), \mathrm{t}(75)=4.645, \mathrm{p}<.0005 ; \mathrm{d})$ the product placement is well positioned $(\mathrm{M}$ $=4.01, \mathrm{SD}=.626), \mathrm{t}(74)=14.002, \mathrm{p}<.005 ; \mathrm{e})$ the product placement is more intrusive $(\mathrm{M}=3.67, \mathrm{SD}=.755)$, $\mathrm{t}(75)=7.746, \mathrm{p}<.0005$ and, $\mathrm{f})$ when exposed to how the product is used $(\mathrm{M}=3.87, \mathrm{SD}=.660), \mathrm{t}(75)=$ $11.468, \mathrm{p}<.0005$.

\section{Recall}

There is consensus that students are: a) able to recall product placements $(\mathrm{M}=3.88, \mathrm{SD}=.692), \mathrm{t}$ $(75)=11.103, \mathrm{p}<.0005 ; \mathrm{b})$ able to recall product placements when a celebrity is featured $(\mathrm{M}=3.87, \mathrm{SD}=$ $.838), \mathrm{t}(75)=9.033, \mathrm{p}<.0005 ; \mathrm{c})$ able to recall product placements that are more obvious or intrusive $(\mathrm{M}=$ $4.05, \mathrm{SD}=.764), \mathrm{t}(75)=12.010, \mathrm{p}<.0005 ; \mathrm{d})$ able to recall product placements better when they have a positive attitude towards the product $(\mathrm{M}=4.16, \mathrm{SD}=.910), \mathrm{t}(75)=11.093, \mathrm{p}<.0005 ; \mathrm{e})$ able to recall product placements better when they have a pre-existing need $(\mathrm{M}=4.09, \mathrm{SD}=.769), \mathrm{t}(75)=12.380, \mathrm{p}<$ .0005 . This hypothesis is accepted as there is strong evidence against the null hypothesis which state that students are unable to recall product placement. The findings support literature. Soba and Aydin (2013) certain brands that are given priority and thus one would easily locate within the scene of a movie, T.V programme, radio or other mediums of communication, there are also those that are given less significance and remain blurred somewhere in the background. Frequency is also important factor

\section{Purchase behaviour}

In terms of purchasing behaviour, results indicate that students have been persuaded to purchase a product after being exposed to it via product placements $(\mathrm{M}=3.49, \mathrm{SD}=.916) \mathrm{t}(75)=4.631, \mathrm{p}<.0005$. This hypothesis is accepted. There is a strong evidence that no way that the students purchase behaviour cannot be triggered by exposure via product placements. Findings supports the literature as Redondo and Bernal (2016) and, Cowley and Barron (2008) confirm that the use of product placement can trigger the formulation of positive brand associations, which in turn influence the purchase behaviour.

Results indicated that students do feel, to a large extent, that product placements are effective, as it has the potential to improve the awareness of a product and allows potential customers to recognise the products in a store. Furthermore, product placements may subconsciously create a desire to purchase the product. From the statistics gathered, organisations need to enhance students' perceptions of product placements. Findings have revealed that it is important when using product placements that the intended target audience can relate to the product and the lifestyle it encourages. In order to improve perceptions, marketers can demonstrate how the product is used, making sure to emphasise the product's main features in a practical way. Ultimately, when choosing to target students, it is important to use product placements effectively and choose to promote a product that fits in with their lifestyle. Products that consumers can relate to and consider useful are ultimately those that they purchase. 
Further conclusions revealed that students who participated in this study felt that, as companies spend large sums of money on these promotional campaigns, the product placements need to be obvious and include a favourable character or celebrity.

\section{Study limitations}

A major limitation of this research study is that data was only collected from one private higher education institution in the Durban region and the results cannot be generalised to depict the views of the entire student body studying at other institutions in South Africa.

\section{Suggestions for future research}

This study adopted a quantitative research approach. In future, the study on how students perceive the effectiveness of product placements may be conducted in another context by adopting qualitative research approach, which will allow the use of other instruments such as interviews and the use of focus group in order to obtain a qualitative insight.

\section{Conclusion}

The results from the study indicated that $76(56 \%)$ of the respondents are aware of the concept of product placements and identified that organisations and brands spend a significant portion of their marketing communication on such efforts. This $56 \%$ is aware that companies strategically place products in a variety of media, such as movies and television programmes. Results indicated that Honours students were more aware of product placements than a greater number of students in their second year of study who were unaware of product placements. In addition, most students within the Faculty of Social Sciences were not aware of the concept. While the research indicated that students do pay attention to product placements, it also revealed that the respondents have selective attention and were more likely to pay attention to product placements when: they have a positive attitude towards the product, the product placement is well positioned and when they are exposed to how the product is used.

The results from the quantitative data analysis indicated that students were more likely to interpret the message in a positive way and develop positive feelings towards product placements when: they have a positive attitude towards the product, they have a pre-existing need; they are exposed to how the product is used and when the product placement is well positioned. The results indicated that students are able to recall products that are strategically placed in movies and television programmes but are able to recall them better when: the product placement is more intrusive; they have a positive attitude towards the product, and they have a pre-existing need.

The aim of this study was to investigate students' perceptions of the effectiveness of product placements and whether product placement is a viable marketing communication tool to use when targeting younger consumers such as students. Based on the results, it appears that most of the respondents are aware of product placements and have been persuaded to purchase a product after being exposed to a product placement. Considering that companies spend large sums of money developing such campaigns, marketers and advertisers perhaps need to first consider the use of other promotional tools in conjunction with product placements, when targeting the student population.

\section{References}

Balasubramanian, S.K., Karrh, J.A. \& Patwardhan, H. (2006). Audience response to product placements: An integrative Framework and Future Research Agenda. Journal of Advertising, 35(3), 115-141.

Begy, G. \& Talwar, V. (2016). The economic worth of product placements in prime-time television shows. International Journal of Market Research, 58(2), 253-275.

Cant, M.C. \& van Heerden, C.H. (2013). Marketing Management: A South African Persepective. 2nd edition. Cape Town: Juta.

Cowley, E., \& Barron, C. (2008). When Product Placement Goes Wrong: The Effects of Program Liking and Placement Prominence. Journal of Advertising, 37(1), 89-98. Download citation:https://doi.org/10.2753/JOA00913367370107.

Creswell, J.W. \& Clark, V.L.P. (2011). Designing and Conducting Mixed Method Research. 2nd ed. London: Sage Publishing Ltd.

Górska-Warsewicz, H. \& Kulykovets, O. (2017). Product Placement as an Effective Tool for the Brand Positioning. Available at: http:/ /dx.doi.org/10.5772/intechopen.69989 
Gupta, P.B. \& Gould, S.J. (1997). Consumers' perceptions of ethics and acceptability of product placements in movies: Product category and individual differences. Journal of Current Issues and Research in Advertising, 19(1), 3750.

Gupta, P.B. \& Lord, K.R. (1998). Product placements in movies: The effect of prominence and mode on audience recall. Journal of Current Issues and Research in Advertising, 20(1), 47-59.

Homer, P.M. (2009). Product placements: The impact of placement type and repetition on attitude. Journal of Advertising, 38(3), 21-31.

Kamleitner, B. \& Jyote, A.K. (2013). How using versus showing interaction between characters and products boosts product placement effectiveness. International Journal of Advertising 32(4), 633-653. Download citation: https://doi.org/10.2501/IJA-32-4-633-653.

Keller, G. (2018). Statistics for Management and Economics. (11 th ed.), Boston: Cengage Learning.

Khan, A., Mahmood, A., Lodhi, R.N. \& Aftab, F. (2016). Influence of Product Placement on Consumer Behavior: The Mediating Roles of Consumer Recognition with Program Celebrity and Ethical Perceptions Towards Product Placement that Leads to Consumer Purchase Intention. Journal of Business Studies, 12(1), 168-184.

Kjærnested, A. \& Nielsen, T.M. (2012). Product placement in TV shows. Available at:

http://studenttheses.cbs.dk/bitstream/handle/10417/3864/adalheidur_kjaernested_og_tine_munkegaard_nielsen.p df?sequence=1 Date accessed: 26 March 2017.

Lacroix, K. \& Martin, N. (2013). How people react to product placement: A comparative study between normal product placement and non-ethical product placement.

http://hh.diva-portal.org/smash/get/diva2:626162/FULLTEXT01.pdf Date accessed: 26 February 2016.

Maree, K. (2007). First steps in research. Pretoria: van Schaik.

Nebenzahl, I.D. \& Secunda, E. (1993). Consumers' Attitudes Toward Product Placement in Movies. International Journal of Advertising, 12(1), 1-11.

Parumasur, S.B. \& Roberts-Lombard, M. (2014). Consumer Behaviour. 3rd edition. Cape Town: Juta.

Redondo, I. \& Bernal, J. (2016). Product placements versus conventional advertising: The impact of brand choice on integrated promotional stimuli into movies. Journal of Promotion Management, 22(6), 773-791.

Russell, C.A. \& Rasolofoarison, D. (2017). Uncovering the power of natural endorsements: a comparison with celebrity-endorsed advertising and product placements. International Journal of Advertising, 36(5), 761-778.

Sabour, N.I., Pillai, D., Gistri, G. \& Balasubramanian, S.K. (2015). Attitudes and related perceptions about product placement: a comparison of Finland, Italy, and the United States. International Journal of Advertising, 35(2), 362387.

Schmoll, N, Hafer, J, Hilt, M, \& Reilly, H. (2006). Baby Boomers' Attitudes Towards Product Placements. Journal of Current Issues E Research in Advertising, 28(2), 33-53.

Soba, M. \& Aydin, M. (2013). Product Placement Efficiency in Marketing Communication Strategy. International Journal of Business and Management, 8(12), 111-116. Online Published: doi: 10.5539/ijbm.v8n12p111URL: http:/ /dx.doi.org/10.5539/ijbm.v8n12p111.

Srivastava, R.K. (2016). Promoting brands through placement in successful and unsuccessful films in emerging markets. Journal of Promotion Management, 22(3), 281-300.

Wiid, J. \& Diggines, C. (2009). Marketing Research. Cape Town: Juta.

Williams, K., Petrosky, A., Hernandez, E. \& Page Jr, R., (2011). Product placement effectiveness: revisited and renewed. Journal of Management and Marketing Research, 7, 1-24. 